RESEARCH REPORT

\title{
Gender differences in progression to AIDS and death from HIV seroconversion in a cohort of injecting dug users from 1986 to 2001
}

\author{
Manuela García de la Hera, Inmaculada Ferreros, Julia del Amo, Patricia García de Olalla, \\ Santiago Pérez Hoyos, Roberto Muga, Jorge del Romero, Rafael Guerrero, Ildefonso Hernández- \\ Aguado, and GEMES*
}

J Epidemiol Community Health 2004;58:944-950. doi: 10.1136/jech.2003.017475

\begin{abstract}
Background: Although the consensus is that gender does not influence HIV progression, its relevance may depend on the setting.

Aim: To study gender differences in HIV progression to AIDS and death from 1986 to 2001 in a cohort of injecting drug user (IDU) seroconverters in Spain.

Methods: Risk of AIDS and death in persons infected for the same length of time were compared through Kaplan-Meier, allowing for late entry, and Cox regression adjusting for gender, age, and calendar period (before 1992, 1992-1995, 1996-1998, 1999-2001) fitted as time dependent covariates.

Results: Of 929 IDU, $24.7 \%$ were women. Median seroconversion year was 1993.3 for men and women. $44 \%$ of women and $34 \%$ of men received antiretroviral therapy. Risk of AIDS was lower in women in univariate (hazard ratio (HR) 0.72; $95 \% \mathrm{Cl}: 0.51$ to 1.01 ) and multivariate analyses (HR $0.7395 \% \mathrm{Cl}: 0.52$ to 1.03). A 46\% reduction in risk of AIDS for period 1999-2001 compared with 1992-1995 was seen in both men and women (HR: $0.56(95 \% \mathrm{Cl}: 0.36$ to 0.87$)$. As for mortality, women's risk of death was lower univariately (HR $0.6795 \% \mathrm{Cl}: 0.45$ to 0.99 ) although compared with 1992-95, men experienced a $34 \%$ reduction in mortality during 1999-2001 (HR $0.6695 \% \mathrm{Cl}: 0.40$ to 1.01 ), which was not statistically significant in women.

Conclusions: HIV progression was lower in female IDU before and after 1997 and their uptake of antiretroviral therapy was higher than male IDU. The inability to detect a reduction in mortality for women during 1999-2001 is probably attributable to lack of power. Differences in severity of addiction, drug using patterns, and competing causes of death may explain these findings.
\end{abstract}

See end of article for authors' affiliations

Correspondence to: Dr M García de la Hera, Departmento de Salud Publica, University Miguel Hernández, Campus de San Juan, Ctra AlicanteValencia, Km.8.7. 03550 San Juan de Alicante. Spain; manoli@umh.es

Accepted for publication 16 February 2004

$\mathrm{T}$ he use of highly active antiretroviral treatment (HAART) in western countries has considerably improved the prognosis of HIV infected subjects with access to these therapies. ${ }^{1-3}$ However, HAART can make inequality in HIV care more visible even in countries with free and universal access to antiretroviral drugs as its benefits at population level will largely depend on the patterns of access to, and utilisation of, HIV care. ${ }^{4}$ Although the consensus seems to be that gender does not influence HIV progression, its relevance may vary depending on the setting.

Women have been reported to have higher lymphocyte CD4 cell counts and lower viral load measurements at equal duration of HIV infection, but these findings seem to have no translation in overall progression rates or response to HAART. ${ }^{5-9}$ Most studies have found no differences in HIV progression to AIDS and death by gender, although some have found differences both before and after HAART. ${ }^{10-16}$ Some have reported faster ${ }^{17}$ and others have reported slower HIV progression. ${ }^{18-20}$ To what extent the underlying mechanisms for these findings are biological or behavioural is difficult to elucidate but the differences in lymphocyte CD4 cell counts and viral load have been detected in women from different transmission categories from different countries ${ }^{5-8}$ and the slower HIV progression has been seen in both heterosexual seroconverters in France and Spanish seroconverters from different transmission categories. ${ }^{18} 20$

Although some of the observed discrepancies may be attributable to differences in study design, biased progression estimates by gender may have also resulted from residual confounding by socioeconomic status resulting from the differences in the transmission categories in both the men and the women being compared. Injecting drug users (IDU) and heterosexual partners of IDU in some countries have poorer access to health care, lower uptake of HAART, ${ }^{21}$ and higher pre-AIDS mortality than gay men. ${ }^{22}$ Few studies have specifically studied the influence of gender on HIV progression among IDU after HAART. ${ }^{23}$

Spain has had one of the largest HIV epidemics in western Europe, which has been largely associated to intravenous drug use. ${ }^{24}{ }^{25}$ HIV/AIDS has also been, until recently, the leading cause of death among young adults. ${ }^{26}$ GEMES, Spanish Multicentre Study Group of Seroconverters, has consistently reported slower HIV progression rates in women before and after HAART, ${ }^{20}{ }^{27}$ although no differences in the population effectiveness of HAART by gender have been shown. ${ }^{20}$ Nevertheless, the heterogeneity of transmission categories within GEMES and the low number of women who are not IDU may hamper the comparisons. The objective of this work is to study differences by gender in HIV progression to AIDS and death in subjects who acquired HIV though injecting drug use from 1986 to 2001. Abbreviations: IDU, injecting drug user; HAART, highly active
antiretroviral treatment

*See the appendix for members of GEMES 


\begin{tabular}{|c|c|c|c|c|c|}
\hline & \multirow{2}{*}{$\frac{\text { Total }}{\text { Number }}$} & \multicolumn{2}{|l|}{ Men } & \multicolumn{2}{|l|}{ Women } \\
\hline & & Number & $\%$ & Number & $\%$ \\
\hline Subjects (n) & 929 & 700 & 75.4 & 229 & 24.7 \\
\hline \multicolumn{6}{|l|}{ Cohorts integrating GEMES } \\
\hline CIPS Valencia & 280 & 203 & 29.1 & 77 & 33.6 \\
\hline Sandoval-Madrid & 64 & 50 & 7.1 & 14 & 6.1 \\
\hline HUGTIP-Badalona & 213 & 1622 & 23.1 & 51 & 22.3 \\
\hline CAS-Barcelona & 157 & 114 & 16.3 & 43 & 18.8 \\
\hline Prisons-Barcelona & 215 & 171 & 24.4 & 44 & 19.2 \\
\hline \multicolumn{6}{|l|}{ Level of education } \\
\hline No formal education & 74 & 61 & 6.4 & 13 & 5.2 \\
\hline Primary education & 357 & 265 & 27.8 & 92 & 36.8 \\
\hline Secondary education & 169 & 141 & 14.8 & 28 & 11.2 \\
\hline University studies & 75 & 71 & 7.5 & 4 & 1.6 \\
\hline Unknown & 528 & 415 & 43.5 & 113 & 45.2 \\
\hline AIDS (\%) & 215 & 172 & 24.5 & 43 & 18.7 \\
\hline AIDS incidence per 100 person years & & 5.1 & & 3.8 & \\
\hline Deaths (\%) & 160 & 130 & 18.6 & 30 & 13.1 \\
\hline Death rate per 100 person years & & 3.5 & & 2.5 & \\
\hline Pre-AIDS deaths (\%of total deaths) & 64 & 52 & 40 & & 30 \\
\hline Year of seroconversion (median) & & \multicolumn{2}{|l|}{ July 1992} & \multicolumn{2}{|c|}{ October 1992} \\
\hline Seroconversion interval (median in years) & 929 & \multicolumn{2}{|l|}{7001.07} & \multicolumn{2}{|c|}{2291.00} \\
\hline Year of beginning of treatment (median) & & \multirow{2}{*}{\multicolumn{2}{|c|}{$\begin{array}{l}\text { April } 1997 \\
25.1\end{array}$}} & \multicolumn{2}{|c|}{ January 1997} \\
\hline Age at seroconversion (median) & & 25.1 & & 24.1 & \\
\hline $\begin{array}{l}\text { Proportion prescribed antiretrovirals } \\
\text { Subjects in each calendar period }\end{array}$ & 337 & 237 & 33.9 & 100 & 43.7 \\
\hline Before 1992 & & 225 & 76.8 & 68 & 23.2 \\
\hline 1992-95 (reference) & & 483 & 74.4 & 166 & 25.6 \\
\hline $1996-98$ & & 488 & 74.3 & 169 & 25.7 \\
\hline 1999-2001 & & 456 & 75.6 & 147 & 24.4 \\
\hline
\end{tabular}

\section{METHODS}

Data from 929 IDU with well recorded HIV seroconversion dates from five established seroconverter cohorts included in GEMES were analysed. The cohorts within GEMES have identified HIV seroconverters either retrospective or prospectively from the 1980s to current date and follow them up over time. All subjects who fulfilled the criteria of seroconverter were included in the study. A seroconverter was defined as a person who had had an HIV negative test previous to the first HIV positive one or had a reported seroconversion illness. Seroconversion was estimated as the midpoint between the last HIV negative and the first HIV positive tests. ${ }^{28}$

Current analyses have used data from five cohorts within GEMES; two cohorts from HIV counselling and testing centres: CIPS (Centres for AIDS Information and Prevention) within the Valencian Community and Centro
Sanitario Sandoval (Centre for Sexually Transmitted Diseases and HIV in Madrid), one cohort from the CAS (centres for care and monitoring drug addicts of Barcelona) led by the Municipal Institute for Public Health (IMSP) of Barcelona, one cohort from Badalona Hospital Universitary Germans Trias i Pujol (detoxification unit), and a cohort recruited in prisons of the autonomous government of Catalonia. More information on the characteristics of these cohorts can be obtained from individual publications. ${ }^{29-31}$

Information on sociodemographic characteristics (age, gender, transmission category (IDU, men who have sex with men: MSM, heterosexuals) and educational level) as well as clinical and inmunological data (number and type of AIDS events, antiretroviral treatments prescribed, lymphocyte CD4 cell counts, HIV-RNA viral load, vital status, and cause of death) were collected.
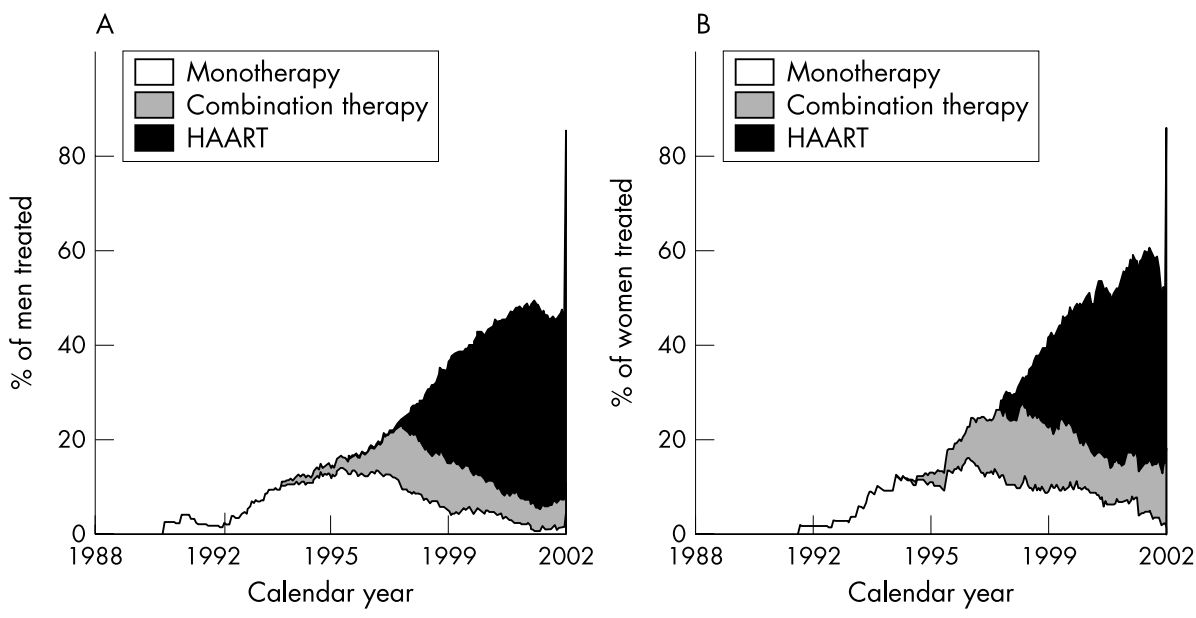

Figure 1 Distribution of treatments over time for (A) men and (B) women in GEMES cohorts of injecting drugs users. 


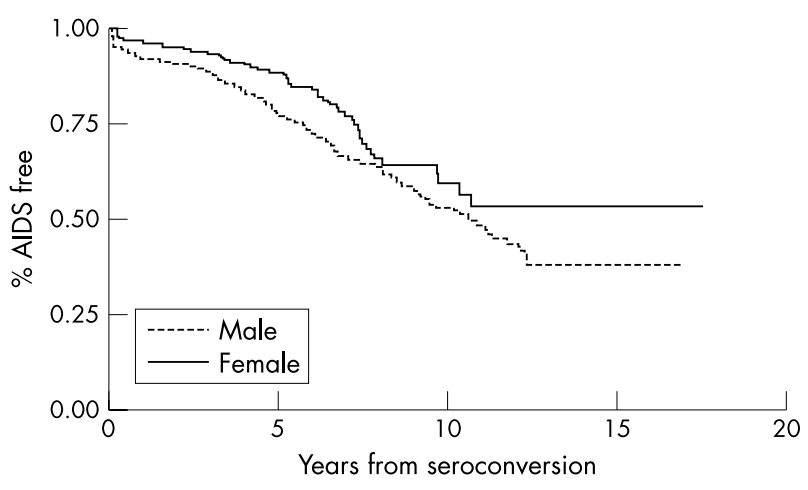

Figure 2 Time to AIDS from seroconversion by gender.

Each of the cohorts within GEMES follows up its seroconverters at the recruiting centres and referral hospitals and follow up is updated yearly.

Additionally, to increase the completeness of the data, cross checks with local and/or national AIDS registers and mortality registers from the different autonomous communities are also performed. ${ }^{32}$ Regional AIDS registers in Spain report to the National AIDS Register and the overall underreporting, $13 \%$, is similar to other European countries. ${ }^{33}$ Cause of death was coded according to the 9th Revision of International Classification ${ }^{34}$ and was further divided into four groups: (a) death from AIDS, (b) death from non-AIDS defining organic causes, (c) death from drug overdose, accidents, and/or violence, (d) death from indeterminate cause.

\section{Statistical analyses}

The demographic and clinical differences by gender were analysed using the two sample $t$ test for normally distributed continuous data, the Mann-Whitney test for non-parametric data, and the $\chi^{2}$ test for frequencies. The analysis of progression to AIDS and death from HIV seroconversion was analysed, allowed for late entry to the date of the first HIV positive test. For these analyses, people who were AIDS free and alive by March 2001 were censored. People with preAIDS mortality were censored as AIDS free at the moment of death for time to AIDS analysis. Survival of HIV positive men was compared with that of HIV positive women infected by HIV for the same length of time through extended KaplanMeier curves and log rank tests. Cox proportional hazards models were used to examine the risk of AIDS and death by gender adjusting for age at seroconversion, transmission category, calendar period, and educational level in those with

Table 2 Relative risk of AIDS from HIV seroconversion in 929 injecting drug users adjusting for calendar period, age, and sex

\begin{tabular}{|c|c|c|}
\hline & \multicolumn{2}{|l|}{ Time to AIDS } \\
\hline & Hazard ratio $(95 \% \mathrm{Cl})$ & p Value \\
\hline \multicolumn{3}{|l|}{ Calendar period* } \\
\hline Before 1992 & $1.10(0.65$ to 1.84$)$ & 0.2 \\
\hline 1992-95 & & \\
\hline 1996-98 & 0.96 (0.66 to 1.39$)$ & \\
\hline $99-2001$ & $0.56(0.36$ to 0.87$)$ & \\
\hline \multirow{2}{*}{\multicolumn{2}{|c|}{$\begin{array}{l}\text { Age (per year increase in } 1.00 \text { (0.97 to } 1.03 \text { ) } \\
\text { age) }\end{array}$}} & 0.858 \\
\hline & & \\
\hline \multicolumn{3}{|c|}{ Sex } \\
\hline Women & $0.73(0.52$ to 1.02$)$ & \\
\hline Men & 1.00 & 0.071 \\
\hline
\end{tabular}

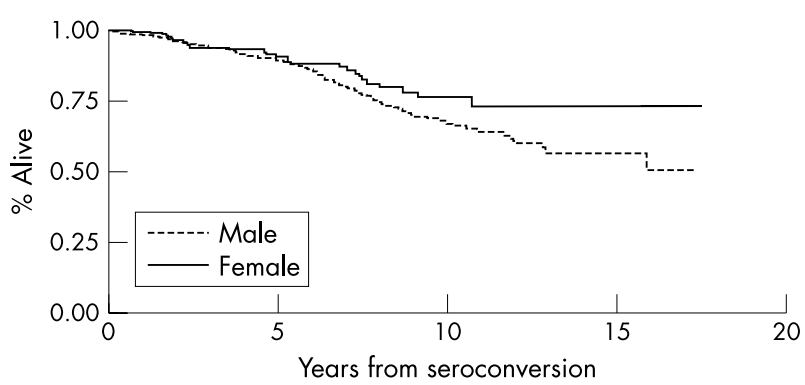

Figure 3 Time to death from HIV seroconversion by gender.

that information available, testing for effect modification. Calendar year at risk was divided in four periods reflecting the availability of antiretroviral drugs in Spain; the reference period, 1992-1995, (double therapy), before 1992 (zidovudine monotherapy), 1996-1998, and 1999-2001, (potent antiretroviral therapy and protease inhibitors)..$^{20}$ Calendar period is used as a proxy to measure the population impact of different antiretroviral regimens available during those years. Calendar period was modelled as a time dependent covariate so each person contributes to the analyses with as many registers of "time periods" he/she has been at risk. Each of these registers has the duration of HIV infection the seroconverter had at the beginning and at the exit of that calendar period, and what was the outcome in terms of AIDS or death. The resulting relative hazard should be interpreted as the excess or the absence in the risk of AIDS and death had the conditions in each period been constant in subjects infected for the same length of time.

Analyses were performed in Stata 7.0 (StataCorp, College Station, TX, USA) using robust methods to estimate confidence intervals. ${ }^{26}$

\section{RESULTS}

These analyses included 929 IDU, 24.7\% of whom were women. Median age at seroconversion was 25 years for men (range 13-49) and 24 years for women (range 15-49). A lower proportion of women had received secondary (11.2\%) and university education (1.6\%) compared with the men; $15 \%$ and $8 \%$ respectively. No differences by gender were observed in either the median year of seroconversion $(p=0.711)$ or in the year of the start of antiretroviral treatment $(\mathrm{p}=0.814)$ (table 1$)$.

We classified someone as lost to follow up when no further data were available on that person after two years from his/ her last contact with the healthcare facility. There were no significant differences in these proportions in men and women ( $26 \%$ and $31 \%$ respectively; $\mathrm{p}=0.119)$.

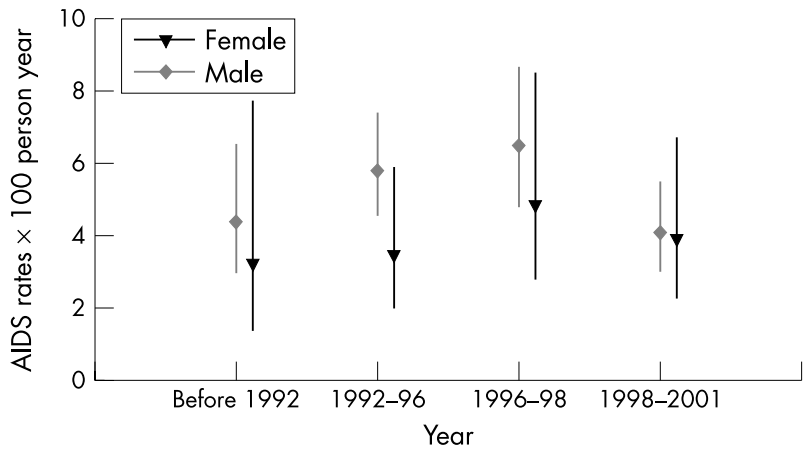

Figure 4 AIDS rates in men and women by calendar period. 
Table 3 Relative risk of death from HIV seroconversion in 929 injecting drug user by sex adjusting for calendar period and age

\begin{tabular}{lll}
\hline & \multicolumn{1}{l}{ Time to death } & \\
\cline { 2 - 3 } & Women & Men \\
\cline { 2 - 3 } & Hazard ratio $(95 \% \mathrm{Cl})$ & Hazard ratio $(95 \% \mathrm{Cl})$ \\
\hline $\begin{array}{l}\text { Calendar period* } \\
\text { Before } 1992\end{array}$ & $3.28(0.90$ to 11.89$)$ & $0.56(0.25$ to 1.22$)$ \\
$1992-95$ & 1 & 1 \\
1996-98 & $2.83(0.98$ to 8.11$)$ & $1.08(0.67$ to 1.72$)$ \\
1999-2001 & $1.23(0.40$ to 3.77$)$ & $0.66(0.40$ to 1.08$)$ \\
Age (per year increase in age) & $1.03(1.00$ to 1.07$)$ & \\
\hline *Calendar period for which each patient contributes to the analysis. & \\
\hline
\end{tabular}

Incidence of AIDS was 5.1 per 100 person years ( 172 cases) for men and 3.8 per 100 person years ( 43 cases) for women. There were 130 deaths among the men giving a mortality rate of 3.5 per 100 person years and 30 deaths in the women, resulting in a mortality rate of 2.5 per 100 person years. The proportion of pre-AIDS deaths was $40 \%$ for men and $30 \%$ for women.

A higher proportion of women $(44 \%)$ received antiretroviral therapy compared with the men (34\%) (table 1 ). Figure $1 \mathrm{~A}$ and $\mathrm{B}$ show the evolution in the uptake of antiretroviral therapy by gender and how the uptake of HAART is higher among women. Of all subjects ever receiving treatment, $40 \%$ received monotherapy as their first option, 26\% combination therapy, 34\% HAART, and there were no differences by gender $(\mathrm{p}=0.79)$. Among subjects prescribed HAART, $50 \%$ were naive $(52 \%$ of the women and $50 \%$ of the men) and $21 \%$ had received combination therapy and $29 \%$ monotherapy previously, and no gender differences were observed $(p=0.82)$. No differences were observed either in the median time from seroconversion to the start of any antiretroviral treatment between women and men (4.0 and 4.40 years respectively, $\mathrm{p}=0.170$ ) or in time from seroconversion to start of HAART.

There were CD4 count data before 24 months from seroconversion in 125 (55\%) women and 371 (53\%) men. There were no significant differences in the median CD4 count by sex; 527 cells $/ \mathrm{ml}$ in women and 484 cells $/ \mathrm{ml}$ in men, $\mathrm{p}=0.097$. Differences were not significant in the median values within six months of the initial AIDS condition in 38 women and 164 men; 221 cells/ml in women and 169 cells/ $\mathrm{ml}$ in men, $\mathrm{p}=0.465$ or in values at death in nine women and 63 men; 353 cells $/ \mathrm{ml}$ in women and 161 cells $/ \mathrm{ml}$ in men, $\mathrm{p}=0.168$. However, women started antiretroviral treatment at higher CD4 counts than men; for 189 women and 490 men, CD4 counts within six months of starting treatment were 440 cells $/ \mathrm{ml}$ and 356 cells $/ \mathrm{ml}$ respectively, $\mathrm{p}<0.001$.

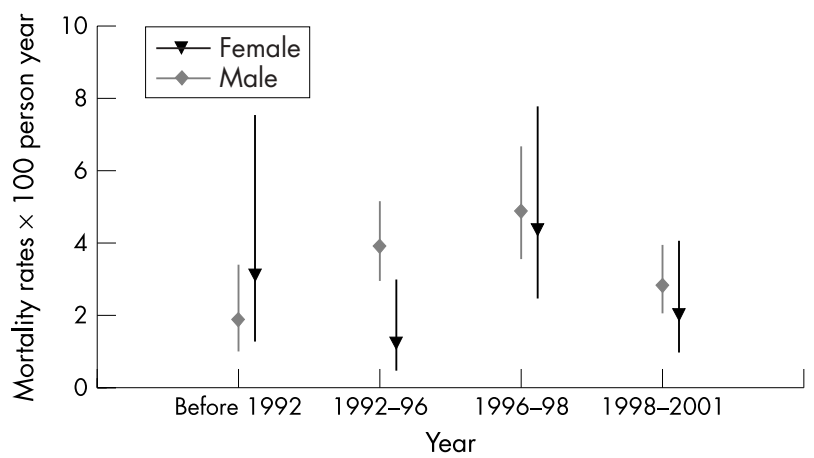

Figure 5 Mortality rates in men and women by calendar period.

\begin{tabular}{ll}
$\begin{array}{l}\text { Table } 4 \text { Effect of gender on calendar period in time to } \\
\text { death from HIV seroconversion }\end{array}$ \\
\hline & \begin{tabular}{l} 
Time to death \\
\cline { 2 - 2 } Hazard ratio $(95 \% \mathrm{Cl})$ women $/$ men $^{*}$
\end{tabular} \\
\hline $\begin{array}{l}\text { Calendar periodt } \\
\text { Before 1992 }\end{array}$ & $2.00(0.70$ to 5.63$)$ \\
$1992-95$ & $0.34(0.13$ to 0.85$)$ \\
$1996-98$ & $0.89(0.47$ to 1.70$)$ \\
$1999-2001$ & $0.63(0.29$ to 1.35$)$ \\
\hline
\end{tabular}

*Adjusted by age; tcalendar period for which each patient contributes to the analysis.

The prevalence of HCV was known in $88 \%$ of the subjects, $89 \%$ of the women and $87 \%$ of the men. HCV prevalence was $73 \%$ in women and $72 \%$ in men, $p=0.700$.

\section{Time to AIDS from HIV seroconversion}

Women had a lower risk of AIDS compared with men in crude analyses although differences did not reach statistical significance. Kaplan-Meier survival curves show how the risk of AIDS was lower in women compared with men (log rank $\mathrm{p}=0.065) ; 47 \%$ of men had developed AIDS 10 years after seroconversion compared with $41 \%$ of women (fig 2 ).

Seventy per cent of all initial AIDS diagnoses were attributable to Pneumocystis cariini pneumonia (PCP) (11\%), pulmonary tuberculosis (TB) $(25 \%)$, and extrapulmonary TB and oesophageal candidiasis (34\%). No important gender differences were observed in the pattern of initial AIDS defining illnesses except for extrapulmonary $\mathrm{TB}$, which was commoner in men (15\%) compared with women $(0 \%)$ $(\mathrm{p}<0.005)$.

Women had a lower hazard of AIDS compared with men in both univariate (hazard ratio (HR) 0.72 ; $95 \% \mathrm{CI}: 0.51$ to 1.01 ) and multivariate analyses that adjusted for age and calendar period (HR 0.73 95\%CI:0.52 to 1.03). Again, differences were in the limit of statistical significance. No interaction was detected between gender and calendar period (log rank test $p=0.657$ ) suggesting that the observed effect of calendar period on time to AIDS, a statistically significant $44 \%$ reduction in the risk of AIDS for calendar period 1999-2001 compared with period 1992-1995, is not different for men and women (table 2 and fig 4). Additional analyses in the subset of persons with information on educational level showed no effect of this variable in progression to AIDS (data not shown).

\section{Survival from HIV seroconversion}

Women showed a lower risk of death compared with men in crude analyses. Kaplan-Meier survival curves show how the risk of death was lower in women compared with men (log rank $\mathrm{p}=0.0479)$; $36 \%$ of the men had died 10 years after 


\section{Key points}

- Among injecting drug users, progression to AIDS and death from HIV seroconversion was slower in women compared with men.

- Compared with men, a higher proportion of female IDU were prescribed antiretroviral regimens and were also started with treatment at higher lymphocyte CD4 counts.

- It is unlikely that these findings are attributable to biological sex differences and healthier behaviours may account for some of the observed differences in the IDU population

seroconversion compared with $24 \%$ of the women (fig 3 ). Also, univariate Cox regression showed a 33\% reduction in the risk of death for the women (HR 0.67 95\%CI:0.45 to 0.99) compared with men.

Crude mortality rates, as shown in figure 5, increase progressively up to calendar period 1996-98 to decrease thereafter, although they follow a different temporal pattern for men and women. The crude risk of death is lower for women in all calendar periods except for before 1992, although differences in that period are not statistically significant; there were only five deaths in women and 11 deaths in men (table 4 and fig 5). From 1992 onwards, female mortality is lower that male mortality although differences are only significant for calendar period 1992-95 $(\mathrm{p}=0.022)$ (table 4 and fig 5).

It can be deduced from the above that gender modified the effect of calendar period on survival although the interation test was of borderline significance (log rank test $\mathrm{p}<0.085$ ) (table 3). Multivariate Cox regression adjusting for age and calendar period showed that compared with 1992-95, men experienced a $34 \%$ reduction in the risk of death for calendar period 1999-2001 (HR 0,66 95\%CI:0.40 to 1.01) while this pattern is not observed in women because their mortality reaches its minimum by 1992-95 (table 3). Nevertheless, compared with calendar period 1996-98, women did experience a reduction in their risk of death by 1999-2001, although it did not reach statistical significance.

Four of the five cohorts had well reported causes of death. No important gender differences were observed in the main groups of causes of death; $60 \%$ of the women and $63 \%$ of the men died of AIDS, $27 \%$ of the women and $21 \%$ of the men died of drug overdose, accidents and/or violence, $4 \%$ of the women and $6 \%$ of the men died from non-AIDS defining illness, and $13 \%$ of the women and $8 \%$ of the men died from unknown causes. Further descriptive analyses looking at causes of death in different calendar periods were difficult to interpret because of small numbers, but it was noticeable that the proportion of deaths from overdose, accidents, and/or violent causes in men was very high (33\%) in 1996-1998 and in women $(13 \%)$. Also, an increase in the proportion of deaths attributable to non-AIDS illness was seen for both men (11\%) and women (17\%) in the last period 1999-2001.

\section{DISCUSSION}

These data show that among persons who acquired HIV though injecting drug use, progression from HIV seroconversion to AIDS and death (1986 to 2001) was lower in women compared with men, although some of these differences were of borderline statistical significance in some calendar periods. Women had slower progression to AIDS compared with men in all calendar periods, as well as higher overall survival, although the relative survival ratio by gender varied overtime; before 1992, mortality was higher in women, although not statistically significant, to become smaller than men thereafter.

Slower HIV progression in female IDU, before and after HAART, had been previously reported in Spain. ${ }^{20} 28$ It is unlikely that these findings are attributable to biological differences or underreporting of AIDS and death in women, ${ }^{32}$ and it seems more plausible that healthier behaviours, as suggested by the higher proportion of women prescribed any antiretroviral drugs and their higher uptake of HAART, may account for some of the observed differences in the IDU population. The fact that a higher proportion of female IDU received more treatment than men could be either the cause or the consequence of their better prognosis. As these are observational data, it is not possible to draw firm conclusions on their directionality. However, as slower HIV progression was also seen in female seroconverters in our setting before HAART, ${ }^{20} 27$ it is more likely that some unmeasured characteristics women have, such as not being a current drug user, make them more suitable to be prescribed treatment. This is also supported by the fact that women were started on treatment at higher lymphocyte CD4 counts than men, not detecting further lymphocyte CD4 differences by sex at seroconversion, AIDS, or death. ${ }^{35}$

Previous research in IDU conducted in Valencia, Spain, showed no differences in access to and utilisation of health services by gender. ${ }^{36}$ In our study, among those who were treated, no gender differences were observed in the time from seroconversion to the start of treatment. HAART in Spain is free of charge for any person, national or foreign, registered in civil registry. Being an active drug user is not a contraindication in itself although there are recommendations to consider starting treatment only in persons who are likely to comply with the regimens and mentions that active drug users should be treated first for their drug related problems. This is why, although data on current drug use in this cohort are not available, we think that the lower proportion of men receiving HAART is likely to be related to their continuation of their injection practices.

Gender differences in HIV related behaviours in IDU have been previously reported both in Europe $e^{37} 38$ and the USA. ${ }^{39}$ Women IDU were more likely to have regular partners who injected drugs ${ }^{37}{ }^{38}$ and had a higher risk of HIV infection because of overlapping sexual and injection partnerships. ${ }^{39}$ Few studies have examined gender differences in HIV progression among IDU after HAART and only studies conducted in Spain have reported better outcomes in women. Muga et al reported lower mortality in HIV positive women compared with HIV positive men in a large cohort of HIV seroprevalent IDU in Spain, but these differences were not observed among HIV negative subjects. ${ }^{310}$ Prins et al found a slower progression to AIDS and death in IDU women registered in the European IDU seroconverter study (where some of the women in GEMES participated) although differences were not statistically significant in the era before HAART. In an Italian seroconverter study, with a large proportion of IDU, no gender differences in HIV progression were observed, although women seemed to have no reduction in AIDS rates after HAART. ${ }^{14}{ }^{15}$ The CASCADE collaboration (where women within GEMES are included) the study with the largest number of seroconverters, has recently reported a slower progression to AIDS and death in women. ${ }^{41}$

A statistically significant reduction of $44 \%$ in the risk of AIDS for calendar period 1999-2001 compared with 1992-95 was observed for both men and women and a 34\% reduction in overall mortality in calendar period 1999-2001 was seen in men. For women, a non-statistically significant reduction in mortality is seen in 1999-2001 compared with 1996-98 
although because of small numbers it is not possible to draw firm conclusions. The effect of calendar period in progression to AIDS and death in our cohort of IDU is observed only for years 1999-2001 and not before, despite HAART being freely available from 1997 onwards. We have previously reported that the population effectiveness of HAART in Spain is delayed in IDU compared with homo/bisexual men and that higher pre-AIDS competing mortality and lower uptake of HAART could be the likeliest causes for it. ${ }^{20}$

While the decrease in the incidence of AIDS related deaths after HAART has been extensively reported 13204243 fewer studies have explored the decrease in pre-AIDS deaths after HAART. ${ }^{44}$ In our study, the proportion of pre-AIDS deaths was very high as it has been at length described in IDU before HAART. ${ }^{22}$ Pre-AIDS deaths seemed to be attributable to different causes over time with a suggestion of a decrease in the number of overdoses, accidents, and/or violent deaths and an increase of non-AIDS illness, although because of small numbers this could not be verified. Therefore, grouping pre-AIDS deaths as it has been done so far seems incorrect in the HAART era given that some of these deaths may be related to drug use (such as drug overdose) and others because of the benefits of the extended survival attributable to HAART ( such as hepatitis $\mathrm{C}$ liver disease). The low number of events in GEMES did not permit the exploration of this in more detail and collaborative analyses with other seroconverter cohorts are needed to conduct competing risk models analyses.

The methodology used in HIV seroconverters cohorts allows us to obtain a public health indicator of the evolution of HIV progression trends in different calendar periods in persons infected by HIV for the same length of time. ${ }^{45} 46$ To minimise losses to follow up, cross checks with AIDS and mortality registers were carried out and these strategies are the same for men and women. ${ }^{32}$ Some of the analyses were underpowered to detect statistically significant differences although in all instances, all trends suggested slower HIV progression in the women. An important limitation is the high rate of losses to follow up but this is inevitable in such difficult to reach populations such as IDU. However, as we crossed check with AIDS and mortality registers, the hard end points of this study, it is unlikely that the results are gender biased.

In summary, the gender differences in HIV disease progression found in IDU in this study are probably attributable to differences in severity of addiction and/or drug using patterns and not biological factors. Further research into behavioural differences in IDU by gender and more detailed cause of death are needed to fully understand the observed trend.

\section{CONTRIBUTORS}

Manuela García de la Hera, Julia del Amo, Patricia García de Olaya, Santiago Pérez-Hoyos, and Ildefonso Hernández initiated this project. Manuela García de la Hera, Patricia García de Olaya, Roberto Muga, Jorge del Romero, Julia del Amo, Rafael Guerrero, and other members of GEMES were responsible for data collection. Inmaculada Ferreros and Santiago Pérez-Hoyos were responsible for data management and statistical analyses. Manuela García de la Hera wrote the first draft of the paper together with Julia del Amo. All authors were involved in the study design and commented on interim drafts. All authors have reviewed the final manuscript.

\footnotetext{
Authors' affiliations

M G de la Hera, J del Amo, I Hernández-Aguado, Department of Public Health, Miguel Hernández University, Alicante, Spain

I Ferreros, S P Hoyos, EVES (Escuela Valenciana de Estudios en Salud), Valencia, Spain

P G de Olalla, Agència de Salut Pública de Barcelona, Spain

R Muga, Hospital Universitari Germans Trias i Pujol, Badalona, Spain
}

J del Romero, Centro Sanitario Sandoval, Madrid and Instituto Madrileño de Salud, Spain

R Guerrero, Red Penitenciaria de Catalunya, Barcelona, Spain

Funding: this work was financed through grants from FIPSE (Fundación para la investigación y la prevención del SIDA en España) integrated by the Spanish Ministry of Health, Abbott Laboratories, Boehringer Ingelheim, Bristol Myers Squibb, GlaxoSmithKline, Merck Sharp and Dohme and Roche), (FIPSE3023/99), FIS (Fondo de Investigación Sanitaria) (FIS 99/0195, 99/1065, 00/294). This study was also supported by funds provided by the Spanish Medical Research Fund (FIS), through Grant C03/09 for RECESP.

Conflicts of interest: none declared.

\section{APPENDIX}

\section{THE MEMBERSHIP OF GEMES INCLUDES Coordinating centre}

Coordinating Centre, Department of Public Health. Miguel Hernández University, Alicante: Ildefonso Hernández Aguado, Julia del Amo.

\section{Centre of data analysis, Valencian School for Health Studies (EVES)}

Centre of Data Analysis, Valencian School for Health Studies (EVES): Santiago Pérez-Hoyos, Inmaculada Ferreros;

\section{Participating centres}

Participating Centres: Centres for AIDS Attention and Prevention (CAS) of Barcelona: Joan Cayla, Patricia Garcia de Olalla, Teresa Brugal; Valencian Centres for AIDS information and Prevention (CIPS), Manuela Garcia de la Hera, Isabel Hurtado, Josefina Belda, Elisa Fernández; Ignacio Alastrue. Hospital Germans Trias I Pujol, Badalona: Roberto Muga, Arantza Sanvicens, Bonaventura Clotet, Jordi Tor; Sandoval-Madrid: Jorge del Romero, Carmen Rodríguez, Soledad Garcia, Montserrat Raposo, Vicente Soriano (for the Grupo de Seroconvertores de la Comunidad de Madrid); Catalonia Prisions: Rafael Guerrero, Andrés Marco; Hospital la Paz: Manolo Quintana, Alicia Barrasa, Julia del Amo, Hospital Vall d'Hebron: Isabel Ruiz, Joan Tussell; Hospital Virgen del Rocío de Sevilla: Rosario Pérez y José Miguel Cisneros; National AIDS Register: Jesús Castilla

\section{REFERENCES}

1 Moore R, Chaisson E. Natural history of HIV infection in the era of combination antiretroviral therapy. AIDS 1999;13:1993-42.

2 Mocroft A, Vella S, Benfield TL, et al. Chaging patterns of mortality across Europe in patients infected with HIV-1. Lancet 1998;352:1725-30.

3 Palella FJ, Delaney KM, Mooman AC, et al. Declining Morbidity and mortality among patients with advanced human immunodeficiency virus infection. N Engl J Med 2001;338:853-60.

4 Dray-Spira R, Lert F. Social health inequalities during the course of chronic HIV disease in the era of highly active antiretroviral therapy. AIDS 2003;17:283-90.

5 Farzadegan H, Hoover DR, Astemborski J, et al. Sex diferences in HIV-1 viral load and progression to AIDS. Lancet 1998;352:1510-14.

6 Prins M, Robersotson JR, Brettle RP, et al. Do gender differences in CD4 counts matter? AIDS 1999;13:2361-4.

7 Napravnik S, Poole Ch, Thomas JC, et al. Gender difference in HIV RNA levels: a meta-analysis of published studies. J AIDS 2002;31:11-19.

8 Gandhi M, Bacchetti P, Miotti P, et al. Does patient sex affect human immnunodeficiency Virus levels? Clin Inf Dis 2002;35:313-22.

9 Hogg RS, Yip B, Chan KJ, et al. Rates of disease progression by baseline CD4 cell count and viral load after initiating triple-drug therapy. JAMA 2001;286:2568-77.

10 Cozzi Lepri A, Pezzotti P, Dorrucci M, et al. HIV disease progression in 854 women and men infected through injecting drug use and heterosexual sex and follow for up to nine years from seroconversion. BMJ 1994;309:1537-42.

11 Sterling TR, Vlahov D, Astemborski J, et al. Initial plasma HIV-1 RNA levels and progression to AIDS in women and men. N Engl J Med 2001;344:720-5.

12 Suligoi B. The natural history of human immunodeficiency virus infection among women as compared with men. Sex Transm Dis 1997;24:77-83.

3 CASCADE Colaboration. Survival after introducition of HAART in people with known duration of HIV infection. Lancet 2000;355:1158-9.

14 Dorrucci $M$, Balducci $M$, Pezzotti $P$, et al. Temporal change in the rate of progression to death among Italians with know date of $\mathrm{HVI}$ seroconvesion: estimates of the population effect of treatment. J AIDS 1999;22:65-70. 
15 Pezzotti P, Galai N, Vladov D, et al. Direct comparison of time to AIDS and infectious disease death between HIV seroconverter injection drug users in Italy and the United States: results from the ALIVA and ISS studies. J AIDS 1999;20:275-82

16 Gange JS, Barrón Y, Greenblatt RM, for the Women's Interagency HIV Study Collaborative Study Group, et al. Effectiveness of highly active antiretroviral therapy among HIV-1 infected women. J Epidemiol Community Health 2002;56:153-9.

17 Melnick S, Sherer R, Louis T, et al. Survival and disease progression according to gender of patients with HIV infection: the Terry Beirn community programs for clinical researche on AIDS. JAMA 1994;272:1915-21.

18 Hubert JB, Ruozioux C, Boufassa F, et al. SEROCO Study Group. Gender, disease progression and response to HAART. XIV international conference on AIDS, Barcelona, 2002:1448.

19 Moore AL, Sabin CA, Johnson MA, et al. Gender and clinical outcomes after highly active antiretroviral treatment: a cohort study. J AIDS 2002;29:197-202.

20 Pérez-Hoyos S, Del Amo J, Muga R, and GEMES, et al. Effectiveness of highly active antiretroviral therapy in Spanish cohorts of HIV seroconverters: differences by transmission category. AIDS 2003;17:1-7.

21 Cascade Collaboration. Changes in the uptake of antiretroviral therapy and survival in people with known duration of infection in Europe: results from CASCADE. HIV Medicine 2000;1:224-31.

22 Prins $M$, Hernandez Aguado IH, Brettle RP, et al. Pre-AIDS mortality from natural causes associated with HIV disease progression: evidence from the European Seroconverter Study among injecting drug users. AIDS 1997; 11:1747-56.

23 Webber MP, Schoenbaum EE, Gourevitch MN, et al. A prospective study of HIV disease progression in female and male drug users. AIDS 1999; 13:257-62

24 Hernández Aguado I, Aviñó MJ, Pérez Hoyos S, et al. Human immunodeficiency virus (HIV) infection in parenteral drug users: evolution of the epidemic over 10 years. Int J Epidemiol 1999;28:335-40.

25 Centro Nacional de Epidemiología. Vigilancia del SIDA en España. Situación al 30 de junio de 2003. Centro Nacional de Epidemiología. http:// www.msc.es/sida/epidemiologia.

26 Castilla J, Martinez de Aragón MV, Gutierrez A, et al. Impact of human immunodeficiency virus infection on mortality among young men and women in Spain. Int J Epidemiol 1997;26:1346-51.

27 GEMES. AIDS incubation period in Spain before highly active antiretroviral therapy. Med Clin (Barc) 2000;115:681-6.

28 Pérez-Hoyos S, Ferreros I, Del Amo J, et al. Imputation of HIV seroconversion time in a cohort hemophiliacs. Gac Sant 2003:17:474-82.

29 Del Amo J, Del Romero J, Barrasa A, and the Grupo de Seroconvertores de la Comunidad de Madrid, et al. Factors influencing HIV progression in a seroconverter cohort in Madrid from 1985 to 1999. Sex Transm Dis 2002;78:255-60.
30 Pérez-Hoyos S, Aviñó MJ, Hernández-Aguado I, et al. AIDS-free time and survival of a injecting drug users HIV seroconversion cohort. Gac Sant 1999; 13:337-45

31 Muga R, Egea JM, Navío M, et al. Mortality in a cohort of intravenous drug users before the introduction of potent HIV therapy. Med Clin (Barc) 1999:1 12:721-5

32 Barrasa A, Castilla J, Pereira J, et al. Estimating the completeness of AIDS reporting in Spain. Gac Sanit 2001;15:482-9

33 Ajdacic-Gross V, Zellweger U, Wang J, et al. How complete is AIDS surveillance in Europe? An eagle eye comparison with mortality data. J Epidemiol Community Health 2001;55:52-6.

34 Ministerio de Sanidad y Consumo Instituto Nacional de la Salud. Clasificación Internacional de Enfermedades, 9th revisión, modificación clínica (CIE-9-MC). Madrid: Ministerio de Sanidad y Consumo, 1988.

35 Pérez Hoyos S, Ferreros I, Sanvicenc A, et al. Evolución del nivel de CD4 tras el inicio del tratamiento HAART en la cohorte de seroconvertores de GEMES. Gac Sanit 2002;16(suppl 1):33-132.

36 García de la Hera M, Ruiz I, Pérez-Hoyos S, et al. Health services utilization according to gender in a cohort of intravenous drug users infected with HIV. Med Clin (Barc) 2003;120:489-93.

37 Davies AG, Dominy NJ, Peters AD, et al. Gender differences in HIV risk behaviour of injecting drug users in Edinburgh. AIDS Care 1996;8:517-27.

38 Garcia de la Hera M, Ruiz I, Hernandez-Aguado I, et al. Gender differences in HIV risk behaviours in intravenous drug users who are not prostitutes. Women Health 2001;34:1-13.

39 Evans JL, Hahn JA, Page-Shafer K, et al. Gender differences in sexual and injection risk behavior among active young injection drug users in San Francisco (the UFO study). Urban Health 2003;80:137-46.

40 Muga R, Roca J, Egea JM, et al. Mortality of HIV-positive and HIV-negative heroin abusers as a function of duration of injecting drug use. J AIDS $2000 ; 23: 332-8$.

41 CASCADE Collaboration. Determinants of survival following HIV-1 seroconversion after the introduction of HAART. Lancet 2003:362:1267-74.

42 Cohen MH, French AL, Benning $L$, et al. Causes of death among women with human immunodeficiency virus infection in the era of combination antiretroviral therapy. Am J Med 2002;113:91-8.

43 Detels R, Muñoz A, McFarlane G, et al. Effectiveness of potent antiretroviral therapy on time to AIDS and death in men with known HIV infection duration. Multicenter AIDS Cohort Study Investigators. JAMA 1998;280:1497-503.

44 Mocroft A, Brettle R, Kirk O, for the EuroSida Study group, et al. Change in the cause of death among HIV positive subjects across Europe: results from the EuroSida study. AIDS 2002;16:1663-11.

45 Muñoz A, Gange SJ, Jacobson LP. Ditinguishing efficacy, individual effectivenes and population effectiveness of therapies. AIDS 2000;14:754-6.

46 Tarwater PM, Mellors J, Gore ME, et al. Methods to asses population effectiveness of therapies in human immunodeficiency virus incident and prevalent cohorts. Am J Epidemiol 2001;154:675-81. 